\title{
Canadian research strategy set for lukewarm welcome?
}

Washington. Plans by Canada's Liberal government to produce a national strategy for science and technology are running late amid allegations that the process, initiated in February 1994, is merely a cover for proposed cuts of up to 20 per cent in the federal science budget.

A draft strategy document prepared for John Manley, the industry minister, was rejected last month by an ad hoc cabinet committee, which considered its recommendations too weak to publish. Manley's staff are revising the document, which is now scheduled to be published in the autumn; but many feel that it is still unlikely to contain any radical proposals.

"The focus of the document will be on principles, such as the role of the government in fostering innovation," says one senior government official involved in the process. "It will be impossible for priorities to be set in, say, biotechnology, because so many different departments are involved."

This will disappoint many Canadian scientists, who are keen for the government to adopt a new strategy for science. Such a strategy is needed, they argue, not only to reverse the proposed budget cuts, but also to stem the continuous drain of scientific talent to the United States, and to restructure a system that is skewed against universities and in favour of government laboratories (see pie chart below).

Manley's review process began energetically enough, attracting thousands of scientists and others to a nationwide series of

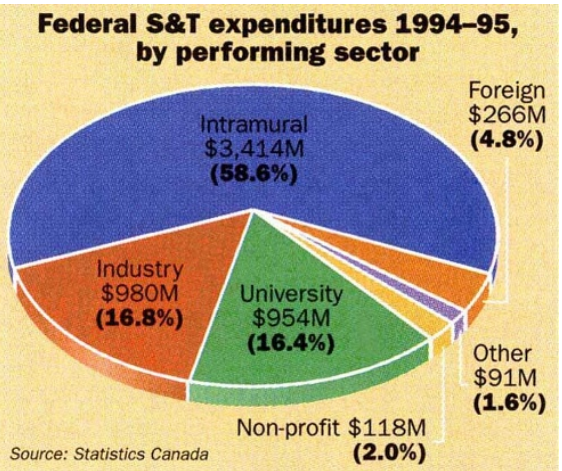

meetings last autumn. But problems became apparent at the beginning of the year, when the schedule started to slip, and a document that was first promised in early 1995 - and then in June - is now due in October.

According to observers, three main factors have caused the slippage. The first, many claim, is a lack of political leadership from the top of government. Advocates of a radical change want a high-ranking science adviser appointed from outside the government, as well as much stronger cabinet involvement in science and technology. But
Jean Chrétien, the prime minister, has shown little interest in the review since it was announced.

Second, many blame the control exercised over the review process by civil servants at Manley's department, known as Industry Canada. The department, together with associated agencies, controls up to 40 per cent of the government's \$6-billion R\&D budget, and its officials are widely considered to be opposed to reforms that could dilute their power.

The third factor is a split within the ruling Liberal party. This is divided over whether its policy for science and technology should be based on a degree of state planning or whether it should be determined by the pressures of the free market.

In April, Chrétien received a report from the National Advisory Board of Science and Technology - made up of leading scientists and industrialists - that called for a cabinet minister to be appointed as a 'champion' of science and technology, for a cabinet committee to deal with such issues and for the appointment of a 'chief science and technology advisor' to the federal government, with his or her own staff.

But the draft document put forward last month rejected the advisory board's proposals, saying that improvements in the running of federally funded science should come from the better management of existing structures. "The government has concluded that the principal issue is not the organizational form of its [science and technology] activities," said the report.

The draft suggested giving existing agencies and departments responsibility for drawing up benchmarks to measure their own success. These efforts would take place against a background of vaguely-worded principles, such as "promoting a stronger science culture" and "capturing the benefits of partnership" with industry.

This was apparently not good enough for the cabinet committee. Nor is it likely to satisfy Canadian scientists. But government officials say that the final document is unlikely to offer much more than the draft version on how science should be run, and the promised national strategy is likely to involve little more than new marching orders for the diffuse array of existing agencies and departments.

These are likely to be told to spend less money, and to do so in ways that boost Canada's economic performance. Action plans from individual departments outlining how these instructions will be met, as well as the final document itself, are now due for publication in early October.

Colin Macilwain

\section{Protestors use World Wide Web in petition against nuclear tests}

Tokyo. Using the power of the Internet, three graduate students at Tokyo University have devised a novel and powerful way to protest against French government plans to restart nuclear tests in the South Pacific.

Seishi Shimizu and Yuichi Nishihara, of the university's physics department, and Kiroh Harada, of its faculty of engineering, have set up a home page on the Worldwide Web on which protesters can register their names on a petition that will be delivered to the French Embassy in Tokyo on 4 August.

At the beginning of this week, over 36,000 names had been gathered from 89 countries. Furthermore, the goals and objectives of the petition, originally transmitted in Japanese and English, had been translated into about 20 different languages including Indonesian, Catalan, Chinese, Dutch, Esperanto, Basque, Finnish, Greek, Polish, Portuguese, Swedish, and Turkish - by some of those who have signed up.

Two of the graduate students started an e-mail chain letter of protest on the Internet on 20 June. But their mailboxes were soon overloaded with thousands of responses arriving each day from around the world. Shimizu had to close down his mail box while Nishihara set up an automatic answering service advising people to switch to the home page. Shimizu says they are "overwhelmed" by the response and are "very sorry" about the problems they caused. But they say that all the e-mail responses have been safely stored, and will be added to the petition.

Shimizu says that the idea was born in response to the fact that the initial reaction of the Japanese public to the planned French nuclear tests has been "very cool". They decided to use the Internet as the "final weapon" to "lower the threshold for action" by individuals both within Japan and around the world.

Of the 36,889 names so far on the petition, Web protest: no 6,961 are from Japan, French testing! which is second only to

Germany, with 9,983 , and names from Japan are pouring in at the rate of about a thousand a day following an appearance of the students on a Japanese television talk show last week.

The Japanese government has already protested strongly to France about the proposed tests. In an unusual move, the Chief Cabinet Secretary, Chews Igarashi, summoned the French ambassador to ask the French government to reverse its decision to resume nuclear tests. 


\section{France thinks small for future satellite plans}

Paris. Spurred on by the success of the experimental satellite Topex-Poseidon, France's National Centre for Space Studies (CNES) has announced plans to develop operational satellites that will be similar in design to Topex but four times smaller. But this ambitious programme, called Topex Poseidon Follow-On (TPFO), has yet to receive a promise of government funding.

Launched jointly with the National Aeronautics and Space Administration (NASA) in August 1992, Topex-Poseidon uses altimetric radar combined with a positioning system in order to measure, with great accuracy and almost instantaneously, average sea levels and the altitude of their oscillation.

Orbiting at a height of $1,300 \mathrm{~km}$, the satellite transmits about 500,000 measurements every ten days. Over a period of three years, Topex has allowed scientists to generate an enormous amount of data about both the topography of the ocean surface and the movements and evolution of ocean currents, as well as data about climate patterns.

One of the observations Topex has made possible is that the average sea level has risen by $4 \mathrm{~mm}$ a year since 1992 . This compares with an average rise of $1.8 \mathrm{~mm}$ a year since the start of the century, based on more conventional forms of measurement.

This rapid rise in sea level is probably the result of various phenomena such as the role of the oceans as a heat sink, the expansion of surface water in the oceans and the melting of glaciers and the polar ice-caps.

CNES officials are delighted with the results, and are keen to move on. "Our technological choice has been confirmed beyond our hopes," says Alain Rattier, head of Earth observation at CNES. "Now we want to do with a satellite of $450 \mathrm{~kg}$ the same as we did with Topex, with its 2 tonnes."

Speaking during a press conference in Paris last week to announce the new programme, André Lebeau, the president of CNES, talked of a series of such operational mini-satellites which, despite an estimated

- Such a move would conventionally have been made by the Foreign Ministry, and indicates an unusually strong protest by the Japanese government. Furthermore, Makiko Tanaka, head of the Science and Technology Agency, has sent a letter to French president, Jacques Chirac, urging him to reconsider the planned tests.

Until the appearance of the home page on the Web, however, there had not been a strong reaction from the Japanese public. For example, there has been no significant movement to boycott French goods as in some other countries - although one major department store has turned over price labels on French goods to discourage consumers from buying them.

The home page is therefore the first sign

\section{IMAGE UNAVAILABLE FOR COPYRIGHT REASONS}

Big brother: French scientists are planning smaller versions of Topex-Poseidon (above).

development cost of a billion French francs (US\$206 million), would be relatively inexpensive while remaining highly reliable.

CNES has also produced a complementary proposal to develop a platform made up of mini-satellites - and provisionally named Proteus - that would be capable of adapta-

\section{MRC cuts funding of alpha-rated projects}

London. Britain's Medical Research Council (MRC) announced this week that the combined effects of financial pressures and high demand from biomedical researchers have made it necessary to reject 70 per cent of grant applications that had received an alpha grading during the review process.

The figures are based on the outcome of decisions over the award last month of $£ 35$ million (US\$56 million) in funding for new research programmes. They contrast strongly to the situation in several recent years when the council says it had been able "to fund all or virtually all long-term research proposals in these high quality categories".

As a result of this financial pressure, the MRC has had $£ 5$ million a year less to spend over the next four years than for the equivalent exercise last year. This situation has

of a significant grassroots movement of protest in Japan. The page declares "stop nuclear tests" and says "we strongly disapprove of the French government's decision to restart nuclear tests". The organizers say they kept the protest simple, and have, for example, not called for a boycott of French goods to encourage the maximum number of people to sign up. But individuals can register their views in an "opinions" corner on the home page.

The organizers will continue to run the home page after they deliver the first petition on 4 August, and will send subsequent updates to the French Embassy. The home page can be accessed at http://www.icepp.s.u-tokyo.ac.jp/ keshi/.

David Swinbanks
क्ष tion to various missions.

The main problem for TPFO is who will fund it. Cooperation with NASA, which had been so successful for Topex-Poseidon, is now in doubt. "NASA is very favourable to this idea, but there are problems with the US Congress," points out Rattier (see Nature 375, 9; 1995).

Congress will apparently have to choose between supporting Topex or the proposed Geosat Follow-On 2 (GFO-2), which is preferred by the US aerospace industry. "This programme will go ahead with or without the Americans," says Rattier.

Before that, however, the programme must be approved by the government, and then the two parliamentary bodies during discussion of the 1996 budget in the autumn. Even if space is still a protected area of French policy, budgetary restrictions are affecting all sectors of government spending. Financial support for TPFO is therefore far from guaranteed. But CNES officials are optimistic.

Catherine Tastemain

been partly created by pressure on the council to switch funding to strategic priorities identified through various government programmes, such as the Technology Foresight Exercise and the new ROPAs (Realizing Our Potential Awards) scheme.

"We understand the need for government financial stringency," the chairman of the MRC, Sir David Plaistow, said in a statement. But "no one should underestimate the damaging impact which this will have on the growing opportunities for high quality medical research work relevant to the health and prosperity of the United Kingdom".

MRC officials are careful to point out that the reduced funding available for highly-rated projects is the result of pressures that have built up over several years - similar difficulties are being report from other research councils - and are, they say, in no way linked to the recent decision to move responsibility for the council's into the Department of Trade and Industry.

Nevertheless, evidence that increased emphasis on strategic priorities may be resulting in reduced funding for investigator-initiated research grants is likely to fuel the continuing debate over the latter move and the government's efforts to harness the science base to the task of wealth creation.

Sir Arnold Wolfendale, for example, the former Astronomer Royal and currently president of the Institute of Physics, wrote in the Financial Times at the beginning of this week that such a move was "incompatible" with the desire, even voiced by industrial leaders, to maintain excellence in many scientific disciplines.

David Dickson 